\title{
A CIDADE INFILTRADA: O AMBIENTE URBANO E OS DESAFIOS DA CULTURA TECNOLÓGICA'
}

Fabio Duarte ${ }^{2}$

\section{INTRODUÇÃO: A RAZÃO DO TEMA}

Deixar de lado problemas "reais" de ordem social, econômica, infraestrutural e política para estudar as relações entre novas tecnologias e cidade parece quase um diletantismo para os profissionais e pesquisadores envolvidos com o planejamento e gestão das cidades. Sobretudo quando se buscam essas relações em obras artísticas.

É justamente a reflexão sobre algumas implicações em como vivemos as cidades contemporâneas e suas transformações a partir das novas tecnologias, buscando insumos em obras de arte e tecnologia, que trata este artigo.

Para iniciar a reflexão, algumas premissas:

a) as inovações tecnológicas têm força transformadora tanto das relações socioeconômicas e na forma como elas se manifestam nas cidades, quanto no modo como arquitetos, urbanistas e gestores pensam o que é o urbano e como elaboram suas projetos urbanísticos e arquitetônicos ${ }^{3}$;

1 Uma primeira versão desse texto foi publicada em espanhol na revista eletrônica Café de las Ciudades, n. 23, Argentina, setembro de 2004.

2 Professor do mestrado em Gestão Urbana da PUCPR. Arquiteto e urbanista pela Universidade de São Paulo, mestre em Multimeios pela Unicamp, doutor em Comunicações e Artes pela Universidade de São Paulo. [fabr@yahoo.com]

3 No livro Arquitetura e Tecnologias de Informação: da revolução industrial à revolução digital (São Paulo: Annablume/Unicamp, 1999) desenvolvi este aspecto, da passagem do século 19 para o 20, com a revolução industrial, passando pelas emergência dos meios de comunicação e a aldeia global nos anos 50, até as tecnologias e arquiteturas contemporâneas. 
b) a necessidade de dar respostas sociais efetivas às transformações que as novas tecnologias trazem aos modos de viver as cidades restringe a possibilidade de profissionais de arquitetura e gestão urbana desviarem-se da concretude de suas ações e de seus efeitos imediatos na sociedade;

c) diversamente dessa responsabilidade dos agentes envolvidos com aspectos sociais das cidades, os artistas não precisam que seus projetos "dêem certo" no sentido de compromisso social, e têm, portanto, maior liberdade de assumir riscos; e, finalmente,

d) sem assumir riscos para depurar ou elaborar conceitos inovadores, e sem assumir riscos de proposições frente aos desafios das relações entre as novas tecnologias e o meio urbano, podemos dar soluções momentâneas, mas não traremos inovações no modo de pensar e trabalhar com assuntos que vivemos e viveremos nas cidades nos próximos anos.

Os espaços virtuais que se infiltram nas cidades e as mudanças epistemológicas e sensoriais que eles trazem à vivência urbana, apontam para uma mudança radical no que entendemos por cidade. Porém, enquanto esses espaços virtuais forem considerados como adendos ao espaço "concreto", como universos paralelos ao "mundo real" ${ }^{\text {, colocamo- }}$ nos na confortável posição de mudar de canal, de separar os momentos de pensar um universo ou o outro - ou, com boa vontade, as relações entre um universo e outro. O desafio é assumir como terreno de reflexão e ação o terreno híbrido entre os dois universos, assumir que um está no outro, que ambos são cada vez mais indissociáveis, e só assim podemos pensar os desafios contemporâneos do que é o espaço urbano.

Este artigo parte de algumas reflexões que vêm sendo apresentadas em outras publicações (apontadas nas referências) e conseqüentes conversas e debates com pensadores das novas tecnologias em diversas áreas de pesquisa. A condução do artigo se dará pela apresentação de

4 William MITCHELL (City of Bits. Boston: MIT Press, 1996) vem trabalhando esta divisão entre a cidade concreta e a cidade virtual, que teriam regras próprias e que viveríamos esses dois universos ao mesmo tempo. 
alguns aspectos conceituais e a apresentação de um projeto de arte e tecnologia onde a cidade foi foco central de atenção - dando pelos estímulos conceituais de pensar a cidade contemporânea, quanto pelas informações trabalhadas e os resultados estéticos do projeto.

\section{O ESPAÇO, O URBANO}

A existência do ser humano implica sua colocação no espaço - seja sua existência material, seja imaginária.

Mas o que é, em síntese, o espaço? Uma das melhores sistematizações desse conceito é do geógrafo Milton Santos (1997), quando o define pela relação dos sistemas de objetos e dos sistemas de ações, sendo seus dois elementos fundamentais os fixos e os fluxos. A apreensão desses elementos envolve características intelectuais, culturais e sensoriais, que, por sua vez, alteram-se em predominância e intensidade dependendo da situação.

A apreensão dos elementos espaciais do recinto onde lemos este artigo envolve sistemas de objetos e ações distintos daqueles que configuram nossos sonhos. Não existe, portanto, um espaço ontológico, mas sim diferentes espaços que são determinados pelas qualidades de seus fluxos e fixos que apreendemos sensorial e intelectualmente.

Vitrúvio definia a arquitetura como uma "medida do homem" frente à natureza. Mas é preciso lembrar que para Vitrúvio a natureza não era apenas o meio natural, mas também o ambiente cultural de sua época. A arquitetura seria então composta de elementos concretos, em relação direta com o ambiente imediato, e também de elementos simbólicos, relacionados à totalidade cultural - da qual a arquitetura era ao mesmo tempo resultado e constituinte.

Sugiro alterarmos o termo arquitetura por cidade, e deste para urbano - lembrando que quando Vitrúvio escreveu, as cidades não eram constituintes primordiais para o entendimento do mundo e dos homens como o são hoje. Não há como pensar o mundo sem pensar o mundo urbano - como vem sendo discutido desde o livro Revolução Urbana, de Henri Lefèbvre (1999). Ao contrário da "cidade", entendida como "um objeto definido e definitivo (...), objetivo imediato para a ação", o urbano aponta para uma "abordagem teórica mais complexa de um objeto virtual 
ou possível" - ou seja, objetos, homens, ações e idéias cuja existência está justamente na inter-relação entre eles. Nas palavras de Lefèbvre, o "urbano... como horizonte, como virtualidade iluminadora."

Feita a alteração de arquitetura para o urbano, mantemos a idéia da cidade como medida cultural do homem no mundo para pensarmos as relações entre o homem, a tecnologia e seu espaço.

Dando mais um passo para montar o painel da discussão, temos em diversos autores (entre eles, destaco Manuel Castells) a exploração dos últimos anos como momento de ruptura cultural radical - e muito disto graças às tecnologias da informação. Vivemos o paradoxo de habitarmos ao mesmo tempo o espaço de fluxos informacionais globais, instantâneos e imateriais e os lugares concretos, materializados nas cidades, acessíveis em percursos lentos (frente à velocidade instantânea dos meios de comunicação).

Essa dicotomia entre os espaços instantâneos e lentos tem sua visão crítica expressas em autores como Arthur and Marilouise Kroker, em seu Digital Delirium (1997), quando escrevem: "Economia rápida, mas trabalhos lentos. Imagens rápidas, mas olhos lentos. (...) Mídia rápida, mas comunicação lenta. Conversa rápida, mas sem pensamento”.

Mas esse mundo informacional está atrelado ao nosso cotidiano: da TV a cabo na sala à Internet no quarto; do débito automático em minha conta no Brasil de uma compra na China aos ambientes Wi-Fi em aeroportos e cafés. E é justamente esse paradoxo entre as instantaneidade global e a aparente lentidão (ou imobilismo?) local que apresenta o mundo contemporâneo - e assim, essa é, também, uma característica do mundo urbano. Como vimos, o urbano não tem os limites na cidade concreta - ela é apenas parte da materialização da cultura humana, da cultura urbana - mundial, informacional.

Retornamos à questão deste artigo, desse espaço híbrido constituído pelas relações interdependentes da cidade concreta de nosso cotidiano e o mundo virtual - também, e cada vez mais, de nosso cotidiano. Neste espaço híbrido Peter Weibel (1994) enxergava a época que então se inaugurava como aquela que seria marcada pelo "trauma do demônico de Maxwell", quando seres e/ou objetos inteligentes interfeririam no mundo 
concreto - sendo esses seres partículas virtuais da arquitetura, responsáveis pelos momentos críticos nas relações entre o humano, o ambiente e as tecnologias. Mas como Selim Koder (1994) ressaltou, essas partículas do virtual inseridas no mundo concreto não nos levaria ao caos, mas sim abrem possibilidades de novas organizações dos sistemas de informação e das cidades. Se lembrarmos que a definição de virtualidade, em sua origem grega, virtus, significa força, potência, a ressalva de Koder ganha relevo.

\section{ESPAÇO E TECNOLOGIA}

A nossa apreensão do espaço implica na inclusão de nossos 5 sentidos e, há séculos, de nossas extensões tecnológicas. Operamos incessantemente num terreno onde trafegam e se misturam diferentes sistemas de signos. Esses diálogos entre linguagens são feitos através das interfaces. Assim, as interfaces não devem ser vistas como a película limítrofe entre pretendidas especificidades de cada mundo (os objetos/fenômenos e seus signos), mas, como sugeriu Siegfried Zielinski (1995), ver as interfaces como instrumentos e modelos conceituais com os quais se possa operar através desses universos de linguagens diferenciadas.

Os dois exemplos de obras de arte e tecnologia que trazemos neste artigo assumem justamente o risco de trabalhar na película limítrofe entre espaços com características diferentes, rompendo-a, inclusive, para levar a reflexão e a execução de suas obras ao espaço híbrido das cidades contemporâneas infiltradas pelos meios tecnológicos.

Os trabalhos do grupo Knowbotic Research envolvem tecnologia, arte, arquitetura e ciência, e se fazem na região sob tensão criativa onde se interpenetram os espaços informacionais e geográficos. O instrumento e o conceito de interface são os knowbots - entendidos como corpos de conhecimento, agentes que transitam entre o território material e o território informacional, contaminando um com o outro, e requalificando a ambos. Os ambientes tecnológicos interativos criados pelo grupo são centrados nas relações entre os usuários e o ambiente mediadas por máquinas inteligentes, como computadores e outros dispositivos eletrônicos. As ações dos usuários refletem-se no conjunto ambiental, assim como as próprias modificações do ambiente modificam a apreensão espacial do usuário. Ao 
enfrentarem as questões das cidades contemporâneas, os trabalhos do Knowbotic ganharam complexidade e novos desafios conceituais, artísticos e tecnológicos, buscando discutir o que chamam da "noção tecnológica da urbanidade" (1997).

As cidades são vistas a partir do conceito do maquínico, de Félix Guattari, para quem a idéia de máquina descola-se da visão mecanicista, atrelada à materialidade de instrumentos tecnológicos, para se colocar na “ordem do saber e não do fazer” (1992) A máquina como uma mediação criativa entre o homem e o meio-ambiente. O maquínico é assim um sistema de "agenciamento" de possíveis, um campo de virtualidades.

Assim, nos trabalhos do Knowbotic Research, o que vemos não é a utilização dos meios digitais para elaboração de representações imagéticas da cidade, e sim como instrumentos para que as pessoas, através de interfaces informacionais, marquem sua presença nesse agenciamento de signos urbanos.

O projeto I0_dencies, desenvolvido em grandes centros urbanos (Tóquio, São Paulo, Veneza, etc.), mantém-se como um dos mais instigantes trabalhos a explorar o espaço híbrido da cidade contemporânea e tecnologias digitais ${ }^{5}$. E por isso voltamos a este exemplo, explorado em trabalho anterior (Duarte, 2002) - afinal, quatro anos após o envolvimento do Knowbotic com grupo de arquitetos de São Paulo para realização do projeto, o I0_dencies voltou como uma das obras de destaque na $2^{\mathrm{a}}$ exposição e simpósio Emoção Art.Ficial, realizada em julho de 2004 pelo Itaú Cutural ${ }^{6}$.

\section{I0_DENCIES: SÃO PAULO}

As cidades são analisadas pelo Knowbotic Research como máquinas urbanas, com a presença crescente de agentes midiáticos dinamizando-as - mas que são normalmente desconsiderados das representações urbanas. Desse pressuposto o grupo construiu um ambiente digital dinâmico. Para início da construção do campo digital, arquitetos e urbanistas em São Paulo

5 Para toda a série de projetos, ver ww.krcf.org/krcfhome/IODENS_SAOPAULO/1IOdencies.htm

6 Ver www.itaucultural.org.br 
alimentaram o banco de dados com fotografias, desenhos, vídeos, sons, pequenos textos teóricos ou poéticos que lhes representasse fragmentos da cidade. A cada um desses elementos os editores ligavam palavras-chave, dispostas no campo visual, a tela do computador, e que, acessadas, traziam as imagens, sons e textos. $\mathrm{O}$ posicionamento e movimento dessas palavras na tela podiam ser feitos por todos os editores e os interessados, via Internet. Algoritmos calculavam a quantidade de vezes que cada palavra era acessada, direção que era movimentada, proximidade a outras palavras, e transformavam esses cálculos em campos de força e fluxos, que começavam a atuar como agentes intrínsecos ao sistema, os knowbots.

Nesse ambiente digital, disponibilizado na Internet, os usuários que estivessem em rede podiam visualizar os fluxos urbanos e também posicionar pólos de atração que modificassem sua trajetória, além de redirecioná-los, ao interferir diretamente nos vetores. $\mathrm{O}$ movimento dos fluxos dependia da presença ativa de operadores dos signos gráficos.

O sistema tecnológico de I0_dencies permitiria ainda que o que é próprio ao território digital das cidades fizesse realmente parte do trabalho. Dados de trânsito aéreo, controles de tráfego viário, ondas de rádio e televisão, chamadas telefônicas e fluxos de informações financeiras dinamizam cotidianamente a cidade, fazendo parte do território digital. É justamente por trabalhar com o mesmo substrato tecnológico e informacional que o projeto I0_dencies poderia incorporar esses dados como seus agentes no processo de agenciamento urbano. Conviveriam então dados que passaram pela leitura dos editores, envolvendo outras formas tecnológicas de apreensão e compreensão urbana (fotos, textos), com dados informacionais próprios ao território digital urbano que foge às representações tradicionais das cidades. O território de $\mathrm{I0}$ dencies tornaria possíveis agenciamentos informacionais das matrizes espaciais próprias às cidades contemporâneas.

Para as exibições em galerias e festivais, foi concebido um campo magnético correspondente ao campo digital criado na Internet, com magnetos correspondendo aos agentes digitais e os movimentos dos usuários, aos fluxos informacionais. Assim, agentes digitais e magnetos se influenciariam reciprocamente, fazendo com que, na instalação, uma pessoa 
que estivesse manipulando um magneto sentisse fisicamente as atrações e repulsas magnéticas originadas pelos atratores manipulados no campo digital, mas pudesse reagir tentando mudá-las através da ação sobre os magnetos. Esses movimentos estariam respondendo e influenciando o agenciamento no campo digital; e vice-versa. A interação em I0_dencies São Paulo criava um território topológico envolvendo signos de diferentes linguagens.

O agenciamento informacional do I0_dencies São Paulo tendia a ser uma metáfora do agenciamento urbano da cidade real. As metáforas são próprias às artes e têm poderes reveladores de relações entre linguagens por vezes não apreendidas na análise racional das informações.

Esse projeto mostra que a linguagem, sendo o modo de organizar e manipular signos, pode ser vista como território informacional. Assim, se a linguagem se transforma, esses territórios também o fazem - já que as idéias que se têm deles devem ser transformadas. Falar de cidades digitais como uma dimensão suplementar às cidades reais é tentar a impossível separação entre sociedade e tecnologia. Ora, elas são interdependentes e se formam reciprocamente.

Claro que continuaremos a caminhar, morar e andar de carro nas cidades. Portanto, ela será sempre um palimpsesto tecnológico, nunca permitindo sua compreensão pela seleção de um único sistema ou linguagem - por mais estimulante que seja.

Apesar de alguns questionamentos que vêm sendo levantados a este projeto do grupo Knowbotic Research, principalmente por urbanistas, arquitetos, historiadores e sociólogos brasileiros, que se dispuseram a conversar longamente com o grupo sobre o projeto (longe dos seminários envolvendo apenas artistas ligados às maravilhas tecnológicas), o projeto I0_dencies é uma das mais inquietantes e profícuas oportunidades para se pensar o espaço tecnológico.

\section{REFERÊNCIAS}

DUARTE, Fábio. Arquitetura e tecnologias de informação. São Paulo e Campinas: Annablume/Unicamp, 1999. (reeditado em 2003) 
DUARTE, Fábio. Crise das matrizes espaciais: arquitetura, cidades, geopolitica e tecnocultura. São Paulo: Perspectiva, 2002.

GUATTARI, Félix. Chaosmose. Paris: Galiée, 1992.

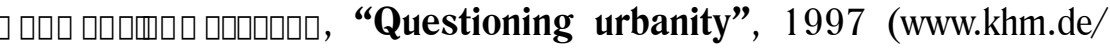
people/krcf)

KODER, Selim. "The transformation of drawing". WEIBEL, Peter (org.). Intelligente Ambiente. Linz: Ars Electronica, 1994.

KROKER, Arthur; KROKER, Marilouise (eds.). "Digital Delirium. Montreal: New World Perspectives", [S.l: s.n],1997.

LEFEBVRE, Henri. A revolução urbana. Belo Horizonte: Universidade Federal de Minas Gerais, 1999

MITCHELL, William. City of Bits. Boston: MIT Press, 1996.

SANTOS, Milton. A natureza do espaço. São Paulo: Hucitec, 1997.

WEIBEL, Peter(org.). Intelligente Ambiente. Linz: Ars Electronica, 1994.

ZIELINSKI, Siegfried. "Paris revue virtuelle", 1995. Disponível em: www.khm.de/ mem_brane/Forum/Phil/Paris.html 
